months exposure the amount and kind of colourchange in the sample were recorded by a LovibondSchofield tentometer. The results can be summarized by stating that for the dyes used, the ultra-violet component of sunlight through glass, or of fluorescent light, is of negligible importance in causing any kind of degradation. The author also states that in the matter of choice of illuminant the situation remains much as before except that intensity of illumination becomes even more important than type of illuminant (daylight, fluorescent or tungsten).

\section{Radio Observations of a Lunar Occultation of the Crab Nebula}

A PAPER by C. H. Costain, B. Elsmore and G. R. Whitfield (Mon. Not. Roy. Astro. Soc., 116, 4 ; 1956) describes the results of radio observations of a lunar occultation of the Crab Nebula on January 24, 1956. Observations of the previous occultation of the same nebula on November 30, 1955, which occurred low in the sky, were seriously affected by man-made interference and only the 1956 occultation is discussed. A short description is given of the aerial system, which was designed to discriminate between the radiation from the source and that from the general galactic structure, and also to allow continuous observation of the source for several minutes on either side of the calculated times of immersion and emersion. The record of the occultation at a wave-length of $3.7 \mathrm{~m}$. and also a mean curve determined from records obtained on days before and after the occultation are given; in addition to the deflexion produced by the Crab Nebula, the records show minor contributions from other sources, especially from nebulosity $I C \mathbf{4 4 3}$ in Gemini. The radiation from the area occulted by the Moon at any time was easily determined from the differences of the curves, this difference being expressed as a fraction of the total intensity.

An important feature revealed by the study is the difference in apparent size of the radio-source as observed by radiation of two different wave-lengths. The radiation at $3.7 \mathrm{~m}$. is confined to a region slightly larger than the visible nebula, but a considerable portion of the radiation at $7.9 \mathrm{~m}$. comes from behind this region a result which suggests that the object extends to a considerably greater radial distance than is revealed in photographs. An explanation of this in terms of the acceleration of fast electrons in weak magnetic fields is given at the end of the paper (cf. Oort, J. H., and Walraven, Th., Bull. Astro. Ned., $12,285 ; 1956)$. Among other matters discussed in the paper may be noted the deductions regarding the lunar atmosphere, based on the difference between the calculated and observed times of obscuration of the source. An electron density of $10^{4} \mathrm{~cm} .^{-3}$ was derived, a figure which corresponds to a surface density of the lunar atmosphere of about $10^{-18}$ of the density of the Earth's atmosphere.

\section{Royal Commission for the Exhibition of $\mid 851$ : Awards for 1957}

The Royal Commission for the Exhibition of 1851 has awarded the following senior studentships for 1957 for research at the universities indicated: J. C. Coulson (Durham), for research in zoology; A. C. Das Chaklader (Leeds), for research in ceramics; G. J. C. Frohnsdorff (Imperial College of Science and Technology, London), for research in physical chemistry; J. A. Schofield (Cambridge), for research in organic chemistry. The Commission has also awarded the following overseas scholarships for 1957 : Australia : L. M. Birt (Melbourne), for research in biochemistry at Oxford ; Miss E. J. Pitman (Sydney), for research in mathematics at Cambridge; $M$. Moyle (Sydney), for research in organic chemistry at Oxford; E. A. Magnusson (New South Wales University of Technology), for research in theoretical chemistry at University College, London. New Zealand: J. E. Titheridge (University of New Zealand), for research in physics at Cambridge. South Africa: C. B. Cottrell (Rhodes), for research in entomology at Cambridge. Republic of Ireland: M. F. Lynch (National University of Ireland), for research in organic chemistry at the Technische Hochschule, Zurich. India: M. L. Dhar (Delhi), for research in organic chemistry at Oxford. Pakistan : S. N. Nabi (Dacca), for research in physical chemistry at Cambridge.

\section{Perkin Centenary Awards}

Mr. J. E. BLoor, of Manchester, has been awarded the Perkin Centenary Fellowship for study in the Department of Chemistry, Manchester College of Science and Technology, on the structure and proper. ties of merocyanine dyes and related compounds. Perkin Centenary Scholarships have been awarded to $\mathrm{Mr}$. James McCartney, of Newtownards, Northern Ireland, tenable at The Queen's University, Belfast ; to Mr. Clive Milne, of East Ardsley, near Wakefield, Yorkshire, tenable at Bradford Technical College; and to Miss Gabrielle Griffin, of Withington, Manchester, tenable at the University of Manchester.

\section{Lady Tata Memorial Trust Awards}

THE following awards for research on leukæmia and allied diseases during the academic year 1957-58 have been made by the Lady Tata Memorial Trust. Grants for Research Expenses : Dr. G. Klein (Karolinska Institute, Stockholm); Dr. M. Bessis (Centre National de Transfusion Sanguine, Paris). Scholarship and Grant for Research Expenses : Dr. G. V. Seaman (Department of Colloid Science, Cambridge). Various awards made to the following in previous years (see Nature, 177, 1208; 1956) have been renewed for a further year: Dr. J. Kieler (Fibiger Laboratory, Copenhagen) ; Dr. M. Seligmann (Institut Pasteur, Paris); Dr. M. Simonsen (Fibiger Laboratory, Copenhagen); Dr. B. Thorell (Karolinska Institute, Stockholm) ; Dr. G. Marinone (University of Pavia); Dr. A. J. Therkelsen (Institute of General Pathology, University of Aarhus).

\section{Special Courses in Higher Techology}

ParT II of the Bulletin of Special Courses in Higher Technology, including management studies and commerce, issued by the London and Home Counties Regional Advisory Council for Higher Technological Education (pp. 61. 1s. 6d.), gives details of courses held in the spring and summer terms. The purpose of the Bulletin is to give publicity to special advanced courses held in the region which do not regularly appear in college calendars or prospectuses as part of a grouped course or as subjects offered for endorsement on Higher National Certificates. The courses are usually part-time evening courses, but the Bulletin also includes special fulltime courses of not more than three months duration. Sessional evening postgraduate courses leading to higher degrees in science and engineering are not included, but colleges offering such courses and 